\title{
DOES MACAULAY DURATION PROVIDE THE MOST COST-EFFECTIVE IMMUNIZATION METHOD - A THEORETICAL APPROACH
}

\author{
Leszek ZAREMBA
}

\author{
Academy of Finance and Business Vistula, Institute of Finance, Warsaw, Poland \\ e-mail: 1.zaremba@vistula.edu.pl
}

\begin{abstract}
In the following, we offer a theoretical approach that attempts to explain (Comments 1-3) why and when the Macaulay duration concept happens to be a good approximation of a bond's price sensitivity. We are concerned with the basic immunization problem with a single liability to be discharged at a future time q. Our idea is to divide the class $\mathrm{K}$ of all shifts a(t) of a term structure of interest rates $\mathrm{s}(\mathrm{t})$ into many classes and then to find a sufficient and necessary condition a given bond portfolio, dependent on a class of shifts, must satisfy to secure immunization at time q against all shifts $a(t)$ from that class. For this purpose, we introduce the notions of dedicated duration and dedicated convexity. For each class of shifts, we show how to choose from a bond market under consideration a portfolio with maximal dedicated convexity among all immunizing portfolios. We demonstrate that the portfolio yields the maximal unanticipated rate of return and appears to be uniquely determined as a barbell strategy (portfolio) built up with 2 zero-coupon bearing bonds with maximal and respective minimal dedicated durations. Finally, an open problem addressed to researchers performing empirical studies is formulated.
\end{abstract}

Keywords: barbell strategy, convexity, dedicated duration, Macaulay duration, unanticipated rate of return.

\section{Introduction}

Consider an investor who possessing $\mathrm{C}$ dollars today must achieve an investment goal of $\mathrm{L}$ dollars $(\mathrm{L}>\mathrm{C})$ $\mathrm{q}$ years from now by means of a purchase of appropriately selected bond portfolio (BP). If not successful, he/she will incur a penalty, while achieving more than L dollars will result in practically no rewards. Such investors are called bond immunizers. It is natural to assume that $\mathrm{C}$ is the present value of $\mathrm{L}$ dollars.

By the term structure of interest rates, one understands a schedule of spot interest rates $s(t)$ which is estimated from the yields of all coupon-bearing bonds available on a given debt market $\mathrm{M}$ under consideration. The basic immunization problem (BIP) relies on a construction of such a bond portfolio $\mathrm{BP}$ with the present value of $\mathrm{C}$ dollars that the single liability to pay $\mathrm{L}$ dollars ( $\mathrm{L}$ is the future value of C) q years from now will be discharged by means of the inflows $\mathrm{c}(\mathrm{t})$ generated by portfolio BP, no matter what shocks/shifts a(t) of $s(t)$ will occur.
The new term structure is always of the form:

$$
\mathrm{s}^{*}(\mathrm{t})=\mathrm{s}(\mathrm{t})+\mathrm{a}(\mathrm{t})
$$

with $a(t)$ standing for a shift / shock of our term structure $s(t)$, which satisfies Assumption 1 only. The function $\mathrm{s}(\mathrm{t})$ can exhibit various behaviors, for example, it can be flat, rising, declining, humped, or twisted. The classical results refer to flat shifts a(t) and flat term structures $\mathrm{s}(\mathrm{t})$, and they go back as far as to the pioneering work of Macaulay (1938), Redington (1952), and Fisher (1971).

In this paper, we approach the BIP by dividing the set $\mathrm{K}$ of all possibly shits a(t) into infinitely many classes $\mathrm{K}_{\mathrm{v}}$ and then solve BIP for each of these classes separately, with durations $\mathrm{D}_{\mathrm{v}}$ accordingly tailored to the specifics of the class $\mathrm{K}_{\mathrm{v}}$. Similar to Zheng in (2002) and (2007), we are not interested in building or borrowing from the literature a more or less accurate stochastic or deterministic model of the term structure $\mathrm{s}(\mathrm{t})$, as is the case in some publications, for example, Bansal and Zhou (2002) and Litterman (1991), simply because the specifics of term structure models will not play any role in our studies, as is stated in our Assumption 1. 


\section{Assumption 1}

All shifts a(t), as well as all realizations of the governing term structure $\mathrm{s}(\mathrm{t})$, are continuous functions.

As of today, however, no one was successful in building up a bond portfolio BP, with the present value of $\mathrm{C}$ dollars, whose value at a future time $\mathrm{q}$ would never be less than the future value of $\mathrm{C}$ dollars (L dollars) at time $\mathrm{q}$, no matter what shocks a(t) of the term structure $\mathrm{s}(\mathrm{t})$ will occur in the future.

As a matter of fact, it was demonstrated (Corollary 2) in a recent paper by Zaremba and Rządkowski (2016) that given an arbitrary bond portfolio BP, the set of all continuous shocks a(t) of any continuous term structure $s(t)$, against which BP is immunized, is an $(m-1)$ dimensional linear subspace in the $\mathrm{m}$-dimensional linear space $\mathrm{K}$ of all continuous shifts $\mathrm{a}(\mathrm{t})$, with $\mathrm{m}$ standing for the number of instances when BP promises to pay cash (coupons or par values)

Our goal in this paper is fourfold:

(i) to divide set $\mathrm{K}$ into infinitely many classes $\mathrm{K}_{\mathrm{v}}$;

(ii) for each class $\mathrm{K}_{\mathrm{v}}$ (one of them will comprise all parallel shifts), to find a sufficient and necessary condition, a given bond portfolio BP must satisfy to secure immunization at time q against all shifts $a(t)$ from class $K_{v}$; from now on, the set of these immunizing portfolios $\mathrm{BP}_{\mathrm{v}}$ against shocks $a(t)$ from class $K_{v}$ will be denoted by $\Phi_{v}$

(iii) to identify a bond portfolio $\mathrm{BP}_{\mathrm{v}} * \in \Phi_{v}$ with the highest convexity; and

(iv) finally, to find a bond portfolio with maximal unanticipated rate of return among all $\mathrm{BP}_{v}$ $\in \Phi_{v}$.

We will shortly see that set $\Phi_{v}$ of all immunizing bond portfolios against shifts a(t) from class $\mathrm{K}_{\mathrm{v}}$ consists of portfolios such as $\mathrm{BP}_{\mathrm{v}}=\left(\mathrm{w}_{1}, \mathrm{w}_{2}, \ldots, \mathrm{w}_{\mathrm{m}}\right)$ whose weights $\mathrm{W}_{\mathrm{i}}$ satisfy Equation (2) and (2a).
The opposite (in some sense) problem, although closely related, was tackled in two recent papers by Rzadkowski and Zaremba (2010; 2016) where the main task was to characterize all shifts $a(t)$ that satisfy Equation (2) for a given specific bond portfolio

$$
\mathrm{BP}=\left(\mathrm{w}_{1}, \mathrm{w}_{2}, \mathrm{w}_{3}, \ldots, \mathrm{w}_{\mathrm{m}}\right) .
$$

For this purpose, in 2010, a Hilbert space approach was used with orthonormal polynomials playing the major role, while in 2015, the key role was played by the so-called triangular functions.

As far as goals (iii) and (iv) are concerned, similar problems were already investigated in Zaremba (1998) for proportional shifts explored earlier by Elton and Gruber (1995) and next in Zaremba and Smolenski (2000) for the so-called generalized proportional shifts. However, in these two papers, rates of return were compounded in a discrete manner, while the continuous compounding framework is used in this paper.

\section{Initial considerations}

The inspiration as how to divide set $\mathrm{K}$ of all shifts $a(t)$ of the term structure $s(t)$ into infinitely many classes $\mathrm{K}_{\mathrm{v}}$ will come soon from Equation (2).

The resulting division into classes $\mathrm{K}_{\mathrm{v}}$ is presented in Section 3.

Before we arrive at Equation (2), let us remind ourselves that all bond portfolios $\mathrm{BP}_{\mathrm{v}}$ that we will be dealing with are constructed from debt instruments available on a given financial market $M$. Let $t_{0}$ stands for the very moment when an investor bought $\mathrm{BP}_{\mathrm{v}}$, while

$$
\mathrm{t}_{1}, \mathrm{t}_{2}, \mathrm{t}_{3}, \ldots, \mathrm{t}_{\mathrm{m}}=\mathrm{T}
$$

comprise all instances from interval $\left[\mathrm{t}_{0} ; \mathrm{T}\right]$ representing the life span (expressed in years) of portfolio $\mathrm{BP}_{v}$, when either $\mathrm{BP}_{v}$ generates payments $c_{i}$ at $t_{i}$, $1 \leq \mathrm{i} \leq \mathrm{m}$ (in the form of coupons or par values) or the owner of $\mathrm{BP}_{\mathrm{v}}$ expects to be required to pay his/her liabilities at some time q. In other words, we assume that $\mathrm{q}=\mathrm{t}_{\mathrm{n}}$ for some $\mathrm{n}, 1 \leq \mathrm{n} \leq \mathrm{m}$. 
We start by invoking Theorem 1 from Rzadkowski and Zaremba (2000), which can be formulated as the following.

\section{Fact 1}

Let $\mathrm{q}$ denotes a future date when a single liability of $\mathrm{L}$ dollars has to be discharged by means of the cumulated value of the inflows generated by some bond portfolio BP whose present value equals the present value of L. In addition, let Assumption 1 holds.

Then the payment of $\mathrm{L}$ dollars at time $\mathrm{q}$ will be guaranteed (immunization will be secured), provided the following necessary and sufficient condition, having nothing to do with the kind of dynamics of the continuous term structure $s(t)$ of interest rates, but referring solely to its continuous shifts $a(t)$ holds:

$$
\mathrm{a}(\mathrm{q}) \mathrm{q}=\sum_{\mathrm{i}=1}^{\mathrm{i}=\mathrm{m}} \mathrm{t}_{\mathrm{i}} \cdot \mathrm{w}_{\mathrm{i}} \cdot \mathrm{a}\left(\mathrm{t}_{\mathrm{i}}\right)
$$

with

$$
\mathrm{w}_{\mathrm{k}}=\frac{\mathrm{c}_{\mathrm{k}} \cdot \exp \left(-\mathrm{s}\left(\mathrm{t}_{\mathrm{k}}\right) \cdot \mathrm{t}_{\mathrm{k}}\right)}{\sum_{\mathrm{i}=1}^{\mathrm{i}=\mathrm{m}} \mathrm{c}_{\mathrm{i}} \cdot \exp \left(-\left(\mathrm{t}_{\mathrm{i}}\right) \cdot \mathrm{t}_{\mathrm{i}}\right)}
$$

standing for the weight of the cash $\mathrm{c}_{\mathrm{k}}, 1 \leq \mathrm{k} \leq \mathrm{m}$, payable by $\mathrm{BP}$ at time $\mathrm{t}_{\mathrm{k}}$.

Looking at (2), one sees that what really matters in Equation (2) are the values of $a(t)$ at instances $t_{1}$, $\mathrm{t}_{2}, \mathrm{t}_{3}, \ldots, \mathrm{t}_{\mathrm{m}}$ only, that is, $\mathrm{a}\left(\mathrm{t}_{\mathrm{i}}\right)$, including $\mathrm{a}(\mathrm{q})$. Let us separately consider 2 cases:
(a) $a(q)=0$
(b) a(q) $\neq 0$

In case of scenario (a), when the new interest rate $\mathrm{s}^{*}(\mathrm{q})$ at time $\mathrm{q}$ remains the same as it was before the shift a(t) has occurred, that is

$$
\mathrm{s}^{*}(\mathrm{q})=\mathrm{s}(\mathrm{q})+\mathrm{a}(\mathrm{q})=\mathrm{s}(\mathrm{q}),
$$

the right-hand side of (2) must be equal to 0 .

\section{Fact 2a}

Assume a shift $a^{*}(\mathrm{t})$ satisfies two conditions:

(i) $a^{*}(\mathrm{q})=0$ and (ii) for all instances $t_{1}, t_{2}, t_{3}, \ldots, t_{m}$, the values $\mathrm{a} *\left(\mathrm{t}_{\mathrm{i}}\right)$ are nonnegative numbers or all $\mathrm{a} *\left(\mathrm{t}_{\mathrm{i}}\right)$ are nonpositive numbers except for $q=t_{n}$.

Then $\mathrm{BP}=\left(\mathrm{w}_{1}, \mathrm{w}_{2}, \ldots, \mathrm{w}_{\mathrm{m}}\right)$ is an immunizing bond portfolio against shift $a^{*}(t)$ if and only if the equalities (4) hold, where

$$
\mathrm{w}_{\mathrm{i}} \cdot \mathrm{a} *\left(\mathrm{t}_{\mathrm{i}}\right)=0,1 \leq \mathrm{i} \leq \mathrm{m}
$$

Proof. Observe that all $\mathrm{t}_{\mathrm{i}}$ are positive numbers, $\mathrm{w}_{\mathrm{k}}$ are nonnegative, and consequently, the right-hand side of Equation (2) must be either

- nonnegative (whenever $\mathrm{a} *\left(\mathrm{t}_{\mathrm{i}}\right)$ are nonnegative) or

- nonpositive (whenever $\mathrm{a} *\left(\mathrm{t}_{\mathrm{i}}\right)$ are nonpositive).

As the right-hand side of Equation (2) equals 0, the condition (4) follows.

\section{Fact 2b}

Assume that a shift $a^{*}(\mathrm{t})$ satisfies two conditions:

(i) a* (q) $=0$ and

(ii) for all instances $t_{1}, t_{2}, t_{3}, \ldots, t_{m}$, the values $\mathrm{a} *\left(\mathrm{t}_{\mathrm{i}}\right)$ are negative numbers or all $\mathrm{a} *\left(\mathrm{t}_{\mathrm{i}}\right)$ are positive numbers except for $q=t_{n}$.

Then the only immunizing bond portfolio against shift $a^{*}(t)$ is the one (if it exists on the debt market $\mathrm{M})$, say $\mathrm{B}^{*}$, that matures at time $\mathrm{q}$ and reduces to a zero-coupon bond. If, however, such $\mathrm{B}^{*}$ is not tradable on bond market $\mathrm{M}$, then there is no immunizing bond portfolio against $\mathrm{a}^{*}(\mathrm{t})$.

Proof. Observe that by virtue of Fact 2a, $\mathrm{w}_{\mathrm{i}} \cdot \mathrm{a} *\left(\mathrm{t}_{\mathrm{i}}\right)=0$.

If a zero-coupon bond $\mathrm{B}^{*}$ maturing at time $\mathrm{q}=\mathrm{t}_{\mathrm{n}}$ is tradable on market $\mathrm{M}$, then condition (4) is satisfied with $\mathrm{w}_{\mathrm{n}}=1, \mathrm{w}_{\mathrm{i}}=0, \mathrm{i} \neq \mathrm{n}$. But, if there is no such bond $\mathrm{B}^{*}$ on market $\mathrm{M}$, then each other immunizing bond $\mathrm{B}$, if existed, would generate at least one payment at some instance $t_{i} \neq q$. This, however, would mean $\mathrm{w}_{\mathrm{i}} \neq 0$, and by virtue of (ii) would lead to the inequality $\mathrm{w}_{\mathrm{i}} \cdot \mathrm{a} *\left(\mathrm{t}_{\mathrm{i}}\right) \neq 0$ that cannot hold because we have already demonstrated that $\mathrm{w}_{\mathrm{i}} \cdot \mathrm{a} *\left(\mathrm{t}_{\mathrm{i}}\right)=0$. The proof is completed. 


\section{Dedicated for class $K_{v}$ duration $D_{v}$ (when $\mathbf{a}(\mathbf{q}) \neq 0$ )}

In what follows we will be dealing with the most general scenario $(b)$ when $a(q) \neq 0$. In such a case, we can rewrite Equation (2) into an equivalent form

$$
\mathrm{q}=\sum_{\mathrm{i}=1}^{\mathrm{i}=\mathrm{m}} \mathrm{t}_{\mathrm{i}} \cdot \mathrm{w}_{\mathrm{i}} \cdot \frac{\mathrm{a}\left(\mathrm{t}_{\mathrm{i}}\right)}{\mathrm{a}(\mathrm{q})}
$$

For each vector

$$
\mathrm{v}=\left(\mathrm{v}_{1}, \mathrm{v}_{2}, \ldots, \mathrm{v}_{\mathrm{m}}\right) \in \mathrm{R}^{\mathrm{m}}
$$

we will define the class $K_{v}$ of those shifts a(t) of the term structure $\mathrm{s}(\mathrm{t})$ for which

$$
\mathrm{v}_{\mathrm{i}}=\frac{\mathrm{a}\left(\mathrm{t}_{\mathrm{i}}\right)}{\mathrm{a}(\mathrm{q})}
$$

For example, when $\mathrm{v}=(1,1, \ldots, 1)$, then the corresponding class $\mathrm{K}_{\mathrm{v}}$ comprises all parallel shifts because each parallel shift $a(t)$, being a constant function, satisfies the condition

$$
1=v_{i}=\frac{a\left(t_{i}\right)}{a(q)}
$$

Clearly, in case (7), our necessary and sufficient immunization condition (5) reduces to the very wellknown fact stating that

$$
\mathrm{q}=\mathrm{D} \text {, with } \mathrm{D}=\sum_{\mathrm{i}=1}^{\mathrm{i}=\mathrm{m}} \mathrm{t}_{\mathrm{i}} \cdot \mathrm{w}_{\mathrm{i}}
$$

being the classical duration.

For each vector

$$
\mathrm{v}=\left(\mathrm{v}_{1}, \mathrm{v}_{2}, \ldots, \mathrm{v}_{\mathrm{m}}\right) \in \mathrm{R}^{\mathrm{m}}
$$

the natural question arises how to solve Equation (5) with unknown variables $\mathrm{w}_{\mathrm{i}}$ that depend on decision variables $c_{i}$ shown in Equation (2) or, equivalently, how to solve the equation

$$
\mathrm{q}=\sum_{\mathrm{i}=1}^{\mathrm{i}=\mathrm{m}} \mathrm{t}_{\mathrm{i}} \cdot \mathrm{w}_{\mathrm{i}} \cdot \mathrm{v}_{\mathrm{i}}
$$

with the known parameters $t_{i}, v_{i}$. Clearly, condition (9a) can be equivalently rewritten as $q=D_{v}$ with:

$$
\mathrm{D}_{\mathrm{v}}=\sum_{\mathrm{i}=1}^{\mathrm{i}=\mathrm{m}} \mathrm{t}_{\mathrm{i}} \cdot \mathrm{w}_{\mathrm{i}} \cdot \mathrm{v}_{\mathrm{i}}
$$

$$
\mathrm{v}=\left(\mathrm{v}_{1}, \mathrm{v}_{2}, \ldots, \mathrm{v}_{\mathrm{m}}\right) \in \mathrm{R}^{\mathrm{m}},
$$

so that Fact 1 can be reformulated as follows.

\section{Fact 3}

Let $\mathrm{q}$ denotes a future date when a single liability of $\mathrm{L}$ dollars has to be discharged by means of the cumulated value of the inflows generated by bond portfolio BP. In addition, let Assumption 1 holds.

Then, assuming that all admissible shifts $\mathrm{a}(\mathrm{t})$ belong to class $\mathrm{K}_{\mathrm{v}}$, the payment of $\mathrm{L}$ dollars at time $\mathrm{q}$ will be secured provided the following necessary and sufficient condition holds:

$$
\begin{aligned}
& \mathrm{D}_{\mathrm{v}}(\mathrm{BP})=\sum_{\mathrm{i}=1}^{\mathrm{i}=\mathrm{m}} \mathrm{t}_{\mathrm{i}} \cdot \mathrm{w}_{\mathrm{i}} \cdot \mathrm{v}_{\mathrm{i}}=\mathrm{q} \text { with } \mathrm{v}_{\mathrm{i}}=\frac{\mathrm{a}\left(\mathrm{t}_{\mathrm{i}}\right)}{\mathrm{a}(\mathrm{q})}, \\
& \mathrm{v}=\left(\mathrm{v}_{1}, \mathrm{v}_{2}, \ldots, \mathrm{v}_{\mathrm{m}}\right),
\end{aligned}
$$

and $\mathrm{w}_{\mathrm{k}}$ standing the weight of the cash $\mathrm{c}_{\mathrm{k}}$, $1 \leq \mathrm{k} \leq \mathrm{m}$, payable by BP at time $\mathrm{t}_{\mathrm{k}}$.

\section{Definition 1}

Let

$$
\mathrm{BP}=\left(\mathrm{w}_{1}, \mathrm{w}_{2}, \mathrm{w}_{3}, \ldots, \mathrm{w}_{\mathrm{m}}\right)
$$

be the bond portfolio with $\mathrm{w}_{\mathrm{i}}$ standing for the weight of the cash $c_{i}$ payable by BP at time $t_{i}$, and let:

$$
\mathrm{v}=\left(\mathrm{v}_{1}, \mathrm{v}_{2}, \ldots, \mathrm{v}_{\mathrm{m}}\right) \in \mathrm{R}^{\mathrm{m}}
$$

be an arbitrary m-dimensional vector. Then the number $D_{v}$ defined by Equation (9b) is said to be the duration dedicated for class $\mathrm{K}_{\mathrm{v}}\left(\mathrm{K}_{\mathrm{v}}\right.$ consists of all shifts a $(t)$ satisfying

$$
\left.\mathrm{v}_{\mathrm{i}}=\frac{\mathrm{a}\left(\mathrm{t}_{\mathrm{i}}\right)}{\mathrm{a}(\mathrm{q})}\right) .
$$

It immediately follows from this definition that a zero-coupon bearing bond maturing at time $t_{i}$ has dedicated duration $D_{v}=t_{i} \cdot v_{i}$ depending on class

$$
\mathrm{K}_{\mathrm{v}}, \mathrm{v}=\left(\mathrm{v}_{1}, \mathrm{v}_{2}, \ldots, \mathrm{v}_{\mathrm{m}}\right) \in \mathrm{R}^{\mathrm{m}} \text {. }
$$

Formula (9b) occurring in the definition of dedicated duration can thus be rephrased as follows. 
If we divide bond portfolio BP into real or imaginary zero-coupon bearing bonds

$$
\mathrm{B}_{\mathrm{i}}, 1 \leq \mathrm{i} \leq \mathrm{m}
$$

with par values of $B_{i}$ being equal to the cash $c_{i}$ payable by BP at instant $t_{i}$, then the dedicated duration of $\mathrm{BP}, \mathrm{D}_{\mathrm{v}}(\mathrm{BP})$, is a weighted average of dedicated durations of $B_{i}$, denoted by $D_{v}\left(B_{i}\right)$, that is:

$$
D_{v}(B P)=\sum_{i=1}^{i=m} t_{i} \cdot w_{i} \cdot v_{i}=\sum_{i=1}^{i=m} w_{i} \quad D_{v}\left(B_{i}\right)
$$

\section{Remark 1}

To avoid in future the possible misunderstandings, let us clarify what we shall mean in this paper by writing "a bond portfolio BP consists of $\mathrm{n}$ different bonds $\mathrm{B}_{\mathrm{k}}$ ". By writing this, we are trying to say that BP is built up with n (say three) types of bonds, for example, BP consists of 210 bonds of type $B_{1}$, 440 bonds of type $B_{2}$, and 170 bonds of type $B_{3}$. In other words, we treat all copies of the same type of bond as just 1 bond ( 1 cash flow) and denote it by $\mathrm{B}_{\mathrm{k}}$ depending on the type of a bond.

Fact 4 tells us that Formula (11a) can be further generalized.

\section{Fact 4}

Let a bond portfolio BP consists of $\mathrm{n}$ different (not necessarily zero-coupon) bonds $B_{k}$ with dedicated durations

$$
\mathrm{D}_{\mathrm{v}}\left(\mathrm{B}_{\mathrm{k}}\right), 1 \leq \mathrm{k} \leq \mathrm{n} .
$$

Then the dedicated for class $\mathrm{K}_{\mathrm{v}}$ duration of BP, $\mathrm{D}_{\mathrm{v}}(\mathrm{BP})$, is given by the formula

$$
\mathrm{D}_{\mathrm{v}}(\mathrm{BP})=\sum_{\mathrm{k}=1}^{\mathrm{k}=\mathrm{n}} \mathrm{w}_{\mathrm{k}} \cdot \mathrm{D}_{\mathrm{v}}\left(\mathrm{B}_{\mathrm{k}}\right)
$$

where each $\mathrm{w}_{\mathrm{k}}, 1 \leq \mathrm{k} \leq \mathrm{n}$, represents the proportion of money spent on the purchase of bond $B_{k}$, expressed as a fraction of the total cost incurred for the purchase of BP.

Proof. Suppose, for the sake of simplicity of presentation, that a bond portfolio BP is built of just two bonds, say $\mathrm{B}^{1}$ and $\mathrm{B}^{2}$, whose dedicated for class $\mathrm{K}_{\mathrm{v}}$ durations $\mathrm{D}_{\mathrm{v}}{ }^{1}$ and $\mathrm{D}_{\mathrm{v}}{ }^{2}$, respectively, satisfy the relationships, by Definition 1,

$$
\begin{aligned}
& \mathrm{D}_{\mathrm{v}}{ }^{1}=\sum_{\mathrm{i}=1}^{\mathrm{m}} \mathrm{t}_{\mathrm{i}} \cdot \frac{\mathrm{c}_{\mathrm{i}}{ }^{1} \cdot \exp \left(-\mathrm{s}\left(\mathrm{t}_{\mathrm{i}}\right) \cdot \mathrm{t}_{\mathrm{i}}\right)}{\operatorname{PV}\left(\mathrm{B}^{1}\right)} \cdot \mathrm{v}_{\mathrm{i}}, \\
& \mathrm{D}_{\mathrm{v}}{ }^{2}=\sum_{\mathrm{i}=1}^{\mathrm{m}} \mathrm{t}_{\mathrm{i}} \cdot \frac{\mathrm{c}_{\mathrm{i}}{ }^{2} \cdot \exp \left(-\mathrm{s}\left(\mathrm{t}_{\mathrm{i}}\right) \cdot \mathrm{t}_{\mathrm{i}}\right)}{\operatorname{PV}\left(\mathrm{B}^{2}\right)} \cdot \mathrm{v}_{\mathrm{i}}
\end{aligned}
$$

with $\mathrm{c}_{\mathrm{i}}{ }^{1}+\mathrm{c}_{\mathrm{i}}{ }^{2}=\mathrm{c}_{\mathrm{i}}$, where $\mathrm{c}_{\mathrm{i}}$ is the cash paid by BP at time $t_{i}$.

Therefore,

$$
\begin{aligned}
& \mathrm{D}_{\mathrm{v}}(\mathrm{BP})= \\
& \sum_{\mathrm{i}=1}^{\mathrm{m}} \mathrm{t}_{\mathrm{i}} \cdot \frac{\left(\mathrm{c}_{\mathrm{i}}{ }^{1}+\mathrm{c}_{\mathrm{i}}{ }^{2}\right) \exp -\mathrm{s}\left(\mathrm{t}_{\mathrm{i}}\right) \cdot \mathrm{t}_{\mathrm{i}}}{\mathrm{PV}(\mathrm{BP})} \cdot \mathrm{v}_{\mathrm{i}}= \\
& \frac{\mathrm{PV}\left(\mathrm{B}^{1}\right)}{\mathrm{PV}(\mathrm{PB})} \cdot \sum_{\mathrm{i}=1}^{\mathrm{m}} \mathrm{t}_{\mathrm{i}} \cdot \frac{\mathrm{c}_{\mathrm{i}}{ }^{1} \exp -\mathrm{s}\left(\mathrm{t}_{\mathrm{i}}\right) \cdot \mathrm{t}_{\mathrm{i}}}{\mathrm{PV}\left(\mathrm{B}^{1}\right)} \cdot \mathrm{v}_{\mathrm{i}}+ \\
& \frac{\mathrm{PV}\left(\mathrm{B}^{2}\right)}{\mathrm{PV}(\mathrm{PB})} \cdot \sum_{\mathrm{i}=1}^{\mathrm{m}} \mathrm{t}_{\mathrm{i}} \cdot \frac{\mathrm{c}_{\mathrm{i}}{ }^{2} \exp -\mathrm{s}\left(\mathrm{t}_{\mathrm{i}}\right) \cdot \mathrm{t}_{\mathrm{i}}}{\mathrm{PV}\left(\mathrm{B}^{2}\right)} \cdot \mathrm{v}_{\mathrm{i}}= \\
& \mathrm{w}_{1} \cdot \mathrm{D}_{\mathrm{v}}{ }^{1}+\mathrm{w}_{2} \cdot \mathrm{D}_{\mathrm{v}}{ }^{2}, \mathrm{w}_{\mathrm{i}}=\frac{\mathrm{PV}\left(\mathrm{B}^{\mathrm{k}}\right)}{\mathrm{PV}(\mathrm{PB})}, 1 \leq \mathrm{k} \leq 2 .
\end{aligned}
$$

Let us now comment a fairly widespread opinion/hypothesis among the researchers that "the simplest Macaulay duration provides the most costeffective immunization method."

\section{Comment 1}

Looking at the definition of dedicated duration $\mathrm{D}_{\mathrm{v}}$ for class $K_{v}$, cf. Equation (9b), one sees that the classical Macaulay duration measure, being identical to our dedicated duration $\mathrm{D}_{\mathrm{v}}$, with

$$
\mathrm{v}=(1,1, \ldots, 1)
$$

is a natural, possible, and the most likely candidate for a one-number sensitivity indicator of a bond's price applicable to all nonparallel shifts of term structure $s(t)$.

To formulate such an opinion/hypothesis, one may not need to do any empirical research of the debt market under consideration. 
However, it seems reasonable and desirable to perform empirical research referring to the computation of vectors

$$
\mathrm{v}=\left(\mathrm{v}_{1}, \mathrm{v}_{2}, \ldots, \mathrm{v}_{\mathrm{m}}\right) \in \mathrm{R}^{\mathrm{m}} \text { with } \mathrm{v}_{\mathrm{i}}=\frac{\mathrm{a}\left(\mathrm{t}_{\mathrm{i}}\right)}{\mathrm{a}(\mathrm{q})}
$$

based on historical data. As a result of such research, it might, for example, happen that on some real debt markets, for example, in Japan, Kazachstan, and Poland, the Macaulay duration would occur not to be "the most cost-effective immunization method."

However, we will prove in Theorem 1 that for those bond immunizers who maximize the unanticipating rate of return, the knowledge of all coordinates of the vector $\mathrm{v}=\left(\mathrm{v}_{1}, \mathrm{v}_{2}, \ldots, \mathrm{v}_{\mathrm{m}}\right)$ is not really needed (see, Comment 2). To prove Theorem 1 in Section 5, we will need the following assumption.

\section{Assumption 2}

All zero-coupon bearing bonds $\mathrm{B}_{\mathrm{i}}$ maturing at time $\mathrm{t}_{\mathrm{i}}, \quad 1 \leq \mathrm{i} \leq \mathrm{m}$, have mutually different dedicated durations, that is, $D_{v}\left(B_{i}\right) \neq D_{v}\left(B_{j}\right)$ if and only if $\mathrm{i} \neq \mathrm{j}$ which is the same as to say that

$$
\mathrm{t}_{\mathrm{i}} \cdot \mathrm{v}_{\mathrm{i}} \neq \mathrm{t}_{\mathrm{j}} \cdot \mathrm{v}_{\mathrm{j}} \leftrightarrow \mathrm{i} \neq \mathrm{j}
$$

\section{Dedicated convexity}

When the term structure of interest rates is a function $s(t)$, then the present value of an arbitrary bond portfolio BP generating cash flow $c_{t}$ is given by the formula

$$
\operatorname{PV}[s(\cdot)]=\sum_{t} c_{t} \cdot \exp [-s(t) \cdot t]
$$

with index $t$ varying over all instances $\mathrm{t}_{1}, \mathrm{t}_{2}, \mathrm{t}_{3}$, $\ldots, \mathrm{t}_{\mathrm{m}}$ when portfolio BP is paying cash. Suppose that immediately after the acquisition of BP, the term structure $s(t)$ shifted to its new level $s *(t)=s(t)+a(t)$ with a continuous shift a(t) according to Assumption 1.
Then, the present value of $\mathrm{BP}$ will also shift to its new value, namely,

$$
\mathrm{PV}[\mathrm{s}(\cdot)+\mathrm{a}(\cdot)]=\sum_{\mathrm{t}} \mathrm{c}_{\mathrm{t}} \cdot \exp [-\mathrm{s}(\mathrm{t})-\mathrm{a}(\mathrm{t})] \cdot \mathrm{t}
$$

where, as previously, $t$ varies over all instances

$$
\mathrm{t}_{1}, \mathrm{t}_{2}, \mathrm{t}_{3}, \ldots, \mathrm{t}_{\mathrm{m}} \text {. }
$$

In order to explain formula (16), let us note that if

$$
\mathrm{h}(\mathrm{s})=\exp [-\mathrm{s} \cdot t] \text {, }
$$

then:

$$
\begin{aligned}
& h^{\prime}(s)=-t \cdot \exp [-s \cdot t] \\
& h^{\prime \prime}(s)=t^{2} \cdot \exp [-s \cdot t]
\end{aligned}
$$

and, consequently, by the Taylor approximation formula, one has

$$
\begin{aligned}
& \mathrm{h}(\mathrm{s}+\mathrm{a})-\mathrm{h}(\mathrm{s}) \approx-\mathrm{t} \cdot \exp [-\mathrm{s} \cdot \mathrm{t}] \cdot \mathrm{a}+ \\
& \frac{1}{2} \mathrm{t}^{2} \exp [-\mathrm{s} \cdot \mathrm{t}] \cdot \mathrm{a}^{2}+\mathrm{O}(\mathrm{a}) \cdot \mathrm{a}^{2},
\end{aligned}
$$

with

$$
\lim \mathrm{O}(\mathrm{a})=0 \text { when } \mathrm{a} \rightarrow 0 .
$$

Generalizing this line of reasoning, we can estimate the unanticipated change in the value of the bond portfolio BP as follows (the term $\sum_{\mathrm{k}=1}^{\mathrm{m}} \mathrm{O}\left[\mathrm{a}\left(\mathrm{t}_{\mathrm{k}}\right)\right] \cdot \mathrm{a}\left(\mathrm{t}_{\mathrm{k}}\right)^{2}$ was omitted):

$$
\begin{aligned}
& \mathrm{PV}[\mathrm{s}(\cdot)+\mathrm{a}(\cdot)]-\mathrm{PV}[\mathrm{s}(\cdot)] \\
& \approx \sum_{\mathrm{k}=1}^{\mathrm{m}}\left\{-\mathrm{t}_{\mathrm{k}} \mathrm{c}_{\mathrm{k}}\left[\exp -\mathrm{s}\left(\mathrm{t}_{\mathrm{k}}\right) \mathrm{t}_{\mathrm{k}}\right] \cdot \mathrm{a}\left(\mathrm{t}_{\mathrm{k}}\right)+\right. \\
& \frac{1}{2}\left[\mathrm{t}_{\mathrm{k}}{ }^{2} \mathrm{c}_{\mathrm{k}} \exp \left[-\mathrm{s}\left(\mathrm{t}_{\mathrm{k}}\right) \mathrm{t}_{\mathrm{k}}\right] \cdot \mathrm{a}^{2}\left(\mathrm{t}_{\mathrm{k}}\right)\right\}
\end{aligned}
$$

Dividing both sides by the present value of BP, that is, $\mathrm{PV}[\mathrm{s}(\cdot)]$, we obtain the following relationship for the unanticipating rate of return (occurring on the left-hand side of the following equality):

$$
\begin{aligned}
& \frac{\operatorname{PV}[\mathrm{s}(\cdot)+\mathrm{a}(\cdot)]-\mathrm{PV}(\mathrm{s}(\cdot)]}{\operatorname{PV}(\mathrm{s}(\cdot)]}= \\
& \sum_{\mathrm{k}=1}^{\mathrm{m}}\left[-\mathrm{t}_{\mathrm{k}} \mathrm{w}_{\mathrm{k}} \mathrm{a}\left(\mathrm{t}_{\mathrm{k}}\right) / \mathrm{a}(\mathrm{q})\right] \mathrm{a}(\mathrm{q})+ \\
& \frac{1}{2} \sum_{\mathrm{k}=1}^{\mathrm{m}}\left\{\mathrm{t}^{2} \mathrm{w}_{\mathrm{k}} \mathrm{a}^{2}\left(\mathrm{t}_{\mathrm{k}}\right)+\mathrm{O}\left[\mathrm{a}\left(\mathrm{t}_{\mathrm{k}}\right)\right] \mathrm{a}\left(\mathrm{t}_{\mathrm{k}}\right)^{2}\right\}
\end{aligned}
$$


Making use of the notion of dedicated duration $\mathrm{D}_{\mathrm{v}}$ for class $\mathrm{K}_{\mathrm{v}}$ of those shifts $\mathrm{a}(\mathrm{t})$ of the term structure of interest rates $s(t)$ for which

$$
\mathrm{v}_{\mathrm{i}}=\frac{\mathrm{a}\left(\mathrm{t}_{\mathrm{i}}\right)}{\mathrm{a}(\mathrm{q})}, \mathrm{v}=\left(\mathrm{v}_{1}, \mathrm{v}_{2}, \ldots, \mathrm{v}_{\mathrm{m}}\right)
$$

one arrives at

$$
\begin{aligned}
& \frac{\operatorname{PV}[\mathrm{s}(\cdot)+\mathrm{a}(\cdot)]-\mathrm{PV}(\mathrm{s}(\cdot)]}{\mathrm{PV}(\mathrm{s}(\cdot)]}=-\mathrm{D}_{\mathrm{v}}(\mathrm{BP}) \cdot \mathrm{a}(\mathrm{q})+ \\
& \frac{1}{2} \sum_{\mathrm{k}=1}^{\mathrm{m}}\left\{\mathrm{t}^{2} \mathrm{w}_{\mathrm{k}} \mathrm{a}^{2}\left(\mathrm{t}_{\mathrm{k}}\right)+\mathrm{O}\left[\mathrm{a}\left(\mathrm{t}_{\mathrm{k}}\right)\right] \mathrm{a}\left(\mathrm{t}_{\mathrm{k}}\right)^{2}\right\} .
\end{aligned}
$$

\section{Definition 2}

Let

$$
\mathrm{BP}=\left(\mathrm{w}_{1}, \mathrm{w}_{2}, \ldots, \mathrm{w}_{\mathrm{m}}\right)
$$

be a bond portfolio BP with weights $\mathrm{w}_{\mathrm{i}}$, and let

$$
\mathrm{v}=\left(\mathrm{v}_{1}, \mathrm{v}_{2}, \ldots, \mathrm{v}_{\mathrm{m}}\right)
$$

be an arbitrary m-dimensional vector.

The number

$$
\mathrm{C}_{\mathrm{v}}(\mathrm{BP})=\frac{1}{2} \sum_{\mathrm{k}=1}^{\mathrm{m}} \mathrm{t}_{\mathrm{k}}^{2} \cdot \mathrm{w}_{\mathrm{k}} \cdot \mathrm{v}_{\mathrm{k}}^{2}
$$

is said to be dedicated for class $\mathrm{K}_{\mathrm{v}}$ convexity of portfolio BP, having in mind that $\mathrm{K}_{\mathrm{v}}$ is a class of shifts $a(t)$ satisfying $v_{i}=\frac{a\left(t_{i}\right)}{a(q)}$. It immediately follows from Definition 2 that the dedicated for class $\mathrm{K}_{\mathrm{v}}$ convexity $\mathrm{C}_{\mathrm{v}}$ of a zero-coupon bond maturing at time $t_{i}$ is given by the formula $\mathrm{C}_{\mathrm{v}}=\frac{1}{2} \cdot \mathrm{t}_{\mathrm{i}}{ }^{2} \cdot \mathrm{v}_{\mathrm{i}}{ }^{2}$.

Formula (18) occurring in the definition of convexity can thus be read as follows: If we divide bond portfolio BP into zero-coupon bearing bonds $B_{i}$, $1 \leq \mathrm{i} \leq \mathrm{m}$, with par values of $\mathrm{B}_{\mathrm{i}}$ being equal to the cash $c_{i}$ paid by BP at instant $t_{i}$, then the dedicated convexity of $\mathrm{BP}, \mathrm{C}_{\mathrm{v}}(\mathrm{BP})$, is a weighted average of dedicated convexities of $B_{i}$, denoted by $C_{v}\left(B_{i}\right)$, that is

$$
\mathrm{C}_{\mathrm{v}}(\mathrm{BP})=\sum_{\mathrm{k}=1}^{\mathrm{k}=\mathrm{m}} \mathrm{w}_{\mathrm{k}} \cdot \mathrm{C}_{\mathrm{v}}\left(\mathrm{B}_{\mathrm{k}}\right) .
$$

Fact 5 tells us that formula (19) can be further generalized (see Remark 1).

\section{Fact 5}

Let a bond portfolio BP consists (is built up) of $n$ different (not necessarily zero-coupon) bonds $B_{k}$, $1 \leq \mathrm{k} \leq \mathrm{n}$, with convexities $\mathrm{C}_{\mathrm{v}}\left(\mathrm{B}_{\mathrm{k}}\right)$. Then the convexity of $\mathrm{BP}$ is a weighted average of convexities $\mathrm{C}_{\mathrm{v}}\left(\mathrm{B}_{\mathrm{k}}\right)$ given by formula(19), with $\mathrm{w}_{\mathrm{k}}$ representing the proportion of money spent on the purchase of bond $\mathrm{B}_{\mathrm{k}}$, expressed as a fraction of the total cost incurred for the purchase of BP.

Proof. Suppose, for the sake of simplicity of presentation, that a bond portfolio $\mathrm{BP}$ is built of bonds $\mathrm{B}^{1}$ and $\mathrm{B}^{2}$, whose convexities $\mathrm{C}_{\mathrm{v}}{ }^{1}$ and $\mathrm{C}_{\mathrm{v}}{ }^{2}$ satisfy by Definition 2 the relationships

$$
\begin{aligned}
& \mathrm{C}_{\mathrm{v}}{ }^{1}=\sum_{\mathrm{i}=1}^{\mathrm{m}} \mathrm{t}_{\mathrm{i}}{ }^{2} \cdot \frac{\mathrm{c}_{\mathrm{i}}{ }^{1} \exp \left(-\mathrm{s}\left(\mathrm{t}_{\mathrm{i}}\right) \cdot \mathrm{t}_{\mathrm{i}}\right)}{\operatorname{PV}\left(\mathrm{B}^{1}\right)} \cdot \mathrm{v}_{\mathrm{i}}{ }^{2}, \\
& \mathrm{C}_{\mathrm{v}}{ }^{2}=\sum_{\mathrm{i}=1}^{\mathrm{m}} \mathrm{t}_{\mathrm{i}}{ }^{2} \cdot \frac{\mathrm{c}_{\mathrm{i}}{ }^{2} \exp \left(-\mathrm{s}\left(\mathrm{t}_{\mathrm{i}}\right) \cdot \mathrm{t}_{\mathrm{i}}\right)}{\operatorname{PV}\left(\mathrm{B}^{2}\right)} \cdot \mathrm{v}_{\mathrm{i}}{ }^{2},
\end{aligned}
$$

with $\mathrm{c}_{\mathrm{i}}{ }^{1}+\mathrm{c}_{\mathrm{i}}{ }^{2}=\mathrm{c}_{\mathrm{i}}$, where $\mathrm{c}_{\mathrm{i}}$ is the cash paid by BP at time $t_{i}$. Therefore,

$$
\begin{aligned}
& \mathrm{C}_{\mathrm{v}}(\mathrm{BP})=\sum_{\mathrm{i}=1}^{\mathrm{m}} \mathrm{t}_{\mathrm{i}}{ }^{2} \cdot \frac{\left(\mathrm{c}_{\mathrm{i}}{ }^{1}+\mathrm{c}_{\mathrm{i}}{ }^{2}\right) \exp \left(-\mathrm{s}\left(\mathrm{t}_{\mathrm{i}}\right) \cdot \mathrm{t}_{\mathrm{i}}\right)}{\mathrm{PV}(\mathrm{BP})} \cdot \mathrm{v}_{\mathrm{i}}{ }^{2}= \\
& \frac{\mathrm{PV}\left(\mathrm{B}^{1}\right)}{\mathrm{PV}(\mathrm{PB})} \cdot \sum_{\mathrm{i}=1}^{\mathrm{m}} \mathrm{t}_{\mathrm{i}}{ }^{2} \cdot \frac{\mathrm{c}_{\mathrm{i}}{ }^{1} \exp \left(-\mathrm{s}\left(\mathrm{t}_{\mathrm{i}}\right) \cdot \mathrm{t}_{\mathrm{i}}\right)}{\mathrm{PV}\left(\mathrm{B}^{1}\right)} \cdot \mathrm{v}_{\mathrm{i}}{ }^{2}+ \\
& \frac{\mathrm{PV}\left(\mathrm{B}^{2}\right)}{\mathrm{PV}(\mathrm{PB})} \cdot \sum_{\mathrm{i}=1}^{\mathrm{m}} \mathrm{t}_{\mathrm{i}}{ }^{2} \cdot \frac{\mathrm{c}_{\mathrm{i}}{ }^{2} \exp \left(-\mathrm{s}\left(\mathrm{t}_{\mathrm{i}}\right) \cdot \mathrm{t}_{\mathrm{i}}\right)}{\mathrm{PV}\left(\mathrm{B}^{2}\right)} \cdot \mathrm{v}_{\mathrm{i}}{ }^{2}= \\
& \mathrm{w}_{1} \cdot \mathrm{C}_{\mathrm{v}}{ }^{1}+\mathrm{w}_{2} \cdot \mathrm{C}_{\mathrm{v}}{ }^{2}, \\
& \mathrm{w}_{\mathrm{k}}=\frac{\mathrm{PV}\left(\mathrm{B}^{\mathrm{k}}\right)}{\mathrm{PV}(\mathrm{PB})}, 1 \leq \mathrm{i} \leq 2 .
\end{aligned}
$$

We can now rephrase formula (17b) into a more convenient (handy) manner as follows. 


\section{Fact 6}

Suppose a bond portfolio BP had been purchased and then the term structure $\mathrm{s}(\mathrm{t})$ of interest rates switched to its new level $s *(t)=s(t)+a(t)$.

Then the unanticipated rate of return resulting from the purchase of BP satisfies the relationship

$$
\begin{aligned}
& \frac{P V[s(\cdot)+a(\cdot)]-P V(s(\cdot)]}{P V(s(\cdot)]} \\
& =-D_{v}(B P) \cdot a(q)+C_{v}(B P) \cdot a^{2}(q)+ \\
& \sum_{k=1}^{m} O\left[a\left(t_{k}\right)\right] \cdot a\left(t_{k}\right)^{2}
\end{aligned}
$$

with $\mathrm{O}(\mathrm{a})$ satisfying (15c). It's worth to notice that $\mathrm{a}^{2}\left(\mathrm{t}_{\mathrm{k}}\right)$ are rather small factors because the absolute values of shifts $a(t)$ are often smaller than $1 \%=0.01$, and pretty often they are even close to 0.001 .

If we apply Equation (21) to a zero-coupon bearing bond maturing at time $t_{i}$, say $B_{i}$, we will obtain that the unanticipated rate of return on

$$
B_{i}=-t_{i} v_{i} a(q)+\frac{1}{2} \cdot t_{i}{ }^{2} v_{i}{ }^{2}{ }^{2}(q)+O\left[a\left(t_{i}\right)\right] \cdot a\left(t_{i}\right)^{2}
$$

provided instantly after the acquisition of bond $B_{i}$, the term structure $s(t)$ shifted to its new level

$$
\mathrm{s}^{*}(\mathrm{t})=\mathrm{s}(\mathrm{t})+\mathrm{a}(\mathrm{t}) \text {, with } \mathrm{v}_{\mathrm{i}}=\frac{\mathrm{a}\left(\mathrm{t}_{\mathrm{i}}\right)}{\mathrm{a}(\mathrm{q})} .
$$

\section{Maximizing the unanticipating rate of return}

In this section, we approach the problems formulated in (iii) and (iv), namely, we want to characterize/identify the bond portfolios $\overline{\mathrm{BP}} \in \Phi_{v}$ that yield the maximal unanticipating rate of return among all portfolios $\mathrm{BP} \in \Phi_{v}$ that, by definition, are immunized against shifts a(t) from class $K_{v}$.

As we have already derived a formula for the unanticipating rate of return in the form of relationship (21) and we know that the dedicated duration $\mathrm{D}_{\mathrm{v}}(\mathrm{BP})=\mathrm{q}$, all we need to do to solve (iv) is to solve (iii), that is, we should maximize the dedicated convexity (18).
The latter can be done by optimally choosing weights $\mathrm{w}_{\mathrm{k}}$ given in Equation (2a) through the appropriate choice of the cash flow $\left\{\overline{\mathrm{c}}_{\mathrm{k}}\right\}, 1 \leq \mathrm{k} \leq \mathrm{m}$, representing our decision variables.

Following Elton and Gruber (1995, p.552), a bond portfolio BP is said to be a barbell strategy (barbell portfolio) if it is built up of just two bonds, say $\mathrm{B}^{1}$ and $\mathrm{B}^{2}$, with significantly different dedicated durations $\mathrm{D}_{\mathrm{v}}{ }^{1}$ and $\mathrm{D}_{\mathrm{v}}{ }^{2}$, respectively.

On the other hand, BP is said to be a focused strategy (focused portfolio) if it consists of several bonds whose dedicated durations $\mathrm{D}_{\mathrm{v}}{ }^{\mathrm{j}}$ are centered around duration of the liability (q, in this context).

\section{Theorem 1}

Suppose Assumptions 1 and 2 hold.

- Let $\mathrm{BP}_{\mathrm{v}} * \in \Phi_{\mathrm{v}}$ be a bond portfolio with the highest dedicated convexity (18) in the class $\Phi_{\mathrm{v}}$ of all bond portfolios immunized against shifts $a(t)$ from set $K_{v}$.

- Let $\mathrm{B}^{\mathrm{k}}, 1 \leq \mathrm{k} \leq \mathrm{n}$, denote those bonds tradable on the debt market $\mathrm{M}$ under consideration from which $\mathrm{BP}_{\mathrm{v}} *$ is built up.

Then $\mathrm{BP}_{\mathrm{v}} *$ is uniquely determined as the barbell strategy built up of two specific zero-coupon bearing bonds, namely, $\mathrm{B}_{\mathrm{s}}$ with the minimal and $\mathrm{B}_{1}$ (maximal) dedicated durations, respectively.

The weights $\overline{\mathrm{X}}_{\mathrm{s}}$ and $\overline{\mathrm{x}}_{1}$ associated with the payments of $\mathrm{BP}_{\mathrm{v}} *$ at instances $\mathrm{t}_{\mathrm{s}}$ and $\mathrm{t}_{1}$ are given by formula (27); they represent the proportions of money spent on the purchase of bonds $\mathrm{B}_{\mathrm{s}}$ and $\mathrm{B}_{1}$, expressed as a fraction of the total cost incurred for the purchase of $\overline{\mathrm{BP}}$.

Proof. Although $\mathrm{BP}_{\mathrm{v}} *$ has been created by purchasing $\mathrm{n}$ bonds $\mathrm{B}^{\mathrm{k}}, 1 \leq \mathrm{k} \leq \mathrm{n}$, tradable on the debt market $\mathrm{M}$, we will look at $\mathrm{BP}_{\mathrm{v}} *$ from a different prospective. Namely, we will say that $\mathrm{BP}_{\mathrm{v}}$ * consists 
of $m$ zero-coupon bonds $B_{i}$, each of them maturing at time $t_{i}$ and generating the same payment of $\bar{c}_{i}$ dollars as $\mathrm{BP}_{\mathrm{v}} *$ is promising to pay $(1 \leq \mathrm{i} \leq \mathrm{m})$.

By virtue of formulas (9b) and (18), the maximization of dedicated convexity $\mathrm{C}_{\mathrm{v}}(\mathrm{BP})$ leads to the following optimization problem, with decision variables $\mathrm{x}_{\mathrm{i}}, \quad 1 \leq \mathrm{i} \leq \mathrm{m}$, representing the proportion of money spent on the purchase of bond $B_{i}$, expressed as a fraction of the total cost incurred for the purchase of BP:

$$
\begin{aligned}
& \max \frac{1}{2} \sum_{\mathrm{i}=1}^{\mathrm{m}} \mathrm{t}_{\mathrm{i}}{ }^{2} \cdot \mathrm{x}_{\mathrm{i}} \cdot \mathrm{v}_{\mathrm{i}}{ }^{2}: \sum_{\mathrm{i}=1}^{\mathrm{m}} \mathrm{x}_{\mathrm{i}}=1 ; \sum_{\mathrm{i}=1}^{\mathrm{m}} \mathrm{t}_{\mathrm{i}} \cdot \mathrm{x}_{\mathrm{i}} \cdot \mathrm{v}_{\mathrm{i}}=\mathrm{q} \\
& \mathrm{x}_{\mathrm{i}} \geq 0
\end{aligned}
$$

As all functions occurring in Equation (22) are linear in $\mathrm{X}_{\mathrm{i}}$, the Kuhn-Tucker conditions

$$
\begin{aligned}
& 0=\frac{\partial \mathrm{L}}{\partial \mathrm{x}_{\mathrm{i}}}\left(\overline{\mathrm{x}}_{1}, \overline{\mathrm{x}}_{2}, \ldots, \overline{\mathrm{x}}_{\mathrm{m}}\right)= \\
& \frac{1}{2} \mathrm{t}_{\mathrm{i}}{ }^{2} \cdot \mathrm{v}_{\mathrm{i}}{ }^{2}+\mu_{1}+\mu_{2} \cdot \mathrm{t}_{\mathrm{i}} \cdot \mathrm{v}_{\mathrm{i}}+\lambda_{\mathrm{i}} \\
& 1 \leq \mathrm{i} \leq \mathrm{m} \\
& \overline{\mathrm{x}}_{\mathrm{i}} \cdot \lambda_{\mathrm{i}}=0, \lambda_{\mathrm{i}} \geq 0, \overline{\mathrm{x}}_{\mathrm{i}} \geq 0,1 \leq \mathrm{i} \leq \mathrm{m}
\end{aligned}
$$

with $\left(\overline{\mathrm{x}}_{1}, \overline{\mathrm{x}}_{2}, \ldots, \overline{\mathrm{x}}_{\mathrm{m}}\right)$ representing the weights of $\mathrm{BP}_{\mathrm{v}} *$ are necessary and sufficient for optimality of $\mathrm{BP}_{\mathrm{v}} *$, with the Lagrangian

$$
\begin{aligned}
& \mathrm{L}\left(\mathrm{x}_{1}, \mathrm{x}_{2}, \ldots, \mathrm{x}_{\mathrm{m}}\right)= \\
& \frac{1}{2} \sum_{\mathrm{i}=1}^{\mathrm{m}}\left(\mathrm{t}_{\mathrm{i}}^{2} \cdot \mathrm{x}_{\mathrm{i}} \cdot \mathrm{v}_{\mathrm{i}}^{2}+\mu_{1} \mathrm{x}_{\mathrm{i}}+\mu_{2} \cdot \mathrm{t}_{\mathrm{i}} \cdot \mathrm{x}_{\mathrm{i}} \cdot \mathrm{v}_{\mathrm{i}}+\lambda_{\mathrm{i}} \cdot \mathrm{x}_{\mathrm{i}}\right) \\
& 1 \leq \mathrm{i} \leq \mathrm{m} .
\end{aligned}
$$

We start by proving that all but two weights $\overline{\mathrm{X}}_{\mathrm{i}}$ are equal to 0 . Suppose on the contrary that

$$
\overline{\mathrm{x}}_{\mathrm{i}} \neq 0, \overline{\mathrm{x}}_{\mathrm{j}} \neq 0, \overline{\mathrm{x}}_{\mathrm{s}} \neq 0 \text {. }
$$

Then by virtue of Equation (23b), we would then infer that

$$
\lambda_{\mathrm{i}}=0, \lambda_{\mathrm{j}}=0, \lambda_{\mathrm{s}}=0,
$$

and then, by invoking Equation (23a), we would get that the quadratic function

$$
\mathrm{f}(\mathrm{t} \cdot \mathrm{v})=\frac{1}{2}(\mathrm{t} \cdot \mathrm{v})^{2}+\mu_{1}+\mu_{2} \cdot(\mathrm{t} \cdot \mathrm{v})
$$

would be equal to 0 for three distinct (by virtue of Assumption 2) roots $t_{i} v_{i}, t_{j} v_{j}$, and $t_{s} v_{s}$, what is impossible because each polynomial of degree 2 has no more than 2 roots. Thus let $\overline{\mathrm{x}}_{1} \neq 0$ and $\overline{\mathrm{x}}_{\mathrm{s}} \neq 0$ be the two only weights that are different (greater than 0 ), meaning that $\mathrm{BP}_{\mathrm{v}} *$ generates cash in just two instances, $t_{1}$ and $t_{s}$. From Equation (22), we know that

$$
\begin{aligned}
& \mathrm{t}_{1} \cdot \overline{\mathrm{x}}_{1} \cdot \mathrm{v}_{1}+\mathrm{t}_{\mathrm{s}} \cdot \overline{\mathrm{x}}_{\mathrm{s}} \cdot \mathrm{v}_{\mathrm{s}}=\mathrm{q} ; \\
& \overline{\mathrm{x}}_{1}+\overline{\mathrm{x}}_{\mathrm{s}}=1 ; \quad \overline{\mathrm{x}}_{1}>0 ; \quad \overline{\mathrm{x}}_{\mathrm{s}}>0 .
\end{aligned}
$$

This is a system of two equations with two unknown variables $\overline{\mathrm{x}}_{1}$ and $\overline{\mathrm{x}}_{\mathrm{s}}$. Solving it, we obtain the formulas (27) for $\overline{\mathrm{x}}_{1}$ and $\overline{\mathrm{x}}_{\mathrm{s}}$ (without loss of generality one may assume that

$$
\begin{aligned}
& \left.\mathrm{t}_{1} \cdot \mathrm{v}_{1}>\mathrm{q}>\mathrm{t}_{\mathrm{s}} \cdot \mathrm{v}_{\mathrm{s}}\right) \\
& \overline{\mathrm{x}}_{\mathrm{s}}=\frac{\mathrm{t}_{1} \mathrm{v}_{1}-\mathrm{q}}{\mathrm{t}_{1} \mathrm{v}_{1}-\mathrm{t}_{\mathrm{s}} \mathrm{v}_{\mathrm{s}}}, \overline{\mathrm{x}}_{1}=\frac{\mathrm{q}-\mathrm{t}_{\mathrm{s}} \mathrm{v}_{\mathrm{s}}}{\mathrm{t}_{1} \mathrm{v}_{1}-\mathrm{t}_{\mathrm{s}} \mathrm{v}_{\mathrm{s}}},
\end{aligned}
$$

with the remaining variables

$$
\overline{\mathrm{x}}_{\mathrm{i}}=0 \text {. }
$$

We will demonstrate that bonds $\mathrm{B}_{\mathrm{s}}$ and $\mathrm{B}_{1}$ have the shortest and resp. longest dedicated durations and that $\mathrm{BP}_{\mathrm{v}} *$ is uniquely determined. In fact, it follows from Equation (23a) that:

$$
\begin{aligned}
& 0=\frac{\partial \mathrm{L}}{\partial \mathrm{x}_{\mathrm{s}}}\left(\overline{\mathrm{x}}_{1}, \overline{\mathrm{x}}_{2}, \ldots, \overline{\mathrm{x}}_{\mathrm{m}}\right) \text { and } \\
& 0=\frac{\partial \mathrm{L}}{\partial \mathrm{x}_{1}}\left(\overline{\mathrm{x}}_{1}, \overline{\mathrm{x}}_{2}, \ldots, \overline{\mathrm{x}}_{\mathrm{m}}\right), \text { that is, } \\
& 0=\frac{1}{2} \mathrm{t}_{\mathrm{s}}{ }^{2} \cdot \mathrm{v}_{\mathrm{s}}{ }^{2}+\mu_{1}+\mu_{2} \cdot \mathrm{t}_{\mathrm{s}} \cdot \mathrm{v}_{\mathrm{s}}= \\
& \frac{1}{2} \mathrm{t}_{1}{ }^{2} \cdot \mathrm{v}_{1}{ }^{2}+\mu_{1}+\mu_{2} \cdot \mathrm{t}_{1} \cdot \mathrm{v}_{\mathrm{i}}
\end{aligned}
$$

because

$$
\lambda_{\mathrm{s}}=\lambda_{1}=0
$$

by virtue of

$$
\overline{\mathrm{x}}_{\mathrm{s}} \cdot \lambda_{\mathrm{s}}=0=\overline{\mathrm{x}}_{1} \cdot \lambda_{1} \text {. }
$$


From Equation (28), we immediately derive two formulas for $\mu_{1}$, namely,

$$
\begin{aligned}
& \mu_{1}=-\mu_{2} \cdot \mathrm{t}_{\mathrm{s}} \cdot \mathrm{v}_{\mathrm{s}}-\frac{1}{2} \mathrm{t}_{\mathrm{s}}{ }^{2} \cdot \mathrm{v}_{\mathrm{s}}{ }^{2} \text { and } \\
& \mu_{1}=-\mu_{2} \cdot \mathrm{t}_{1} \cdot \mathrm{v}_{1}-\frac{1}{2} \mathrm{t}_{1}{ }^{2} \cdot \mathrm{v}_{1}{ }^{2},
\end{aligned}
$$

the latter resulting in

$$
\mu_{2}=-\frac{1}{2} \cdot\left(\mathrm{t}_{1} \cdot \mathrm{v}_{1}+\mathrm{t}_{\mathrm{s}} \cdot \mathrm{v}_{\mathrm{s}}\right) .
$$

Having proved Equation (30), we infer from Equation (29) that

$$
\mu_{1}=\frac{1}{2} \mathrm{t}_{1} \cdot \mathrm{v}_{1} \cdot \mathrm{t}_{\mathrm{s}} \cdot \mathrm{v}_{\mathrm{s}},
$$

and then substitute Equations (30) and (31) into Equation (23a) to obtain the relationship

$$
\begin{aligned}
0= & \frac{1}{2} \mathrm{t}_{\mathrm{i}}^{2} \cdot \mathrm{v}_{\mathrm{i}}^{2}+\left(\frac{1}{2} \mathrm{t}_{\mathrm{l}} \cdot \mathrm{v}_{\mathrm{l}} \cdot \mathrm{t}_{\mathrm{s}} \cdot \mathrm{v}_{\mathrm{s}}\right)- \\
& \frac{1}{2}\left(\mathrm{t}_{1} \cdot \mathrm{v}_{\mathrm{l}}+\mathrm{t}_{\mathrm{s}} \cdot \mathrm{v}_{\mathrm{s}}\right) \cdot \mathrm{t}_{\mathrm{i}} \cdot \mathrm{v}_{\mathrm{i}}+\lambda_{\mathrm{i}}
\end{aligned}
$$

from which the following formula

$$
\lambda_{\mathrm{i}}=\frac{1}{2}\left(\mathrm{t}_{1} \cdot \mathrm{v}_{1}-\mathrm{t}_{\mathrm{i}} \cdot \mathrm{v}_{\mathrm{i}}\right) \cdot\left(\mathrm{t}_{\mathrm{i}} \cdot \mathrm{v}_{\mathrm{i}}-\mathrm{t}_{\mathrm{s}} \cdot \mathrm{v}_{\mathrm{s}}\right)
$$

can be deduced by performing elementary transformations.

In order to have the necessary condition $\lambda_{i} \geq 0$ satisfied, we must choose $t_{1} \cdot v_{1}$ to be the largest number and $t_{s} \cdot v_{s}$ to be the smallest number among all $t_{i} \cdot v_{i}$.

Such a choice is the same as picking from the market $\mathrm{M}$ two zero-coupon bonds, one $\mathrm{B}_{1}$ with the maximal dedicated duration $\mathrm{t}_{1} \cdot \mathrm{v}_{1}$, and the other bond $\mathrm{B}_{\mathrm{s}}$ with the smallest dedicated duration $t_{s} \cdot v_{s}$

With such a choice of dedicated durations, all three necessary and sufficient conditions, namely,

$$
\overline{\mathrm{x}}_{\mathrm{i}} \cdot \lambda_{\mathrm{i}}=0, \lambda_{\mathrm{i}} \geq 0, \overline{\mathrm{x}}_{\mathrm{i}} \geq 0,1 \leq \mathrm{i} \leq \mathrm{m},
$$

are now satisfied by the barbell bond portfolio $\mathrm{BP}_{\mathrm{v}}$ *, what is clearly seen from Equations (27) and

In this way, we have uniquely identified via formula (27) the weights of the bond portfolio BP with the maximal dedicated convexity.

In order to claim the uniqueness of $\mathrm{BP}_{\mathrm{v}}{ }^{*}$, it is enough to invoke the fact that the present value of $\mathrm{BP}_{\mathrm{v}}$ * equals the present value of liability $\mathrm{L}$ to be paid off at the specified time

$$
\mathrm{q}, \mathrm{t}_{1} \leq \mathrm{q} \leq \mathrm{t}_{\mathrm{m}} .
$$

\section{Concluding remarks}

\section{Comment 2}

It follows from Theorem 1 that what really matters, from the point of view of bond immunizers, are not all coordinates of the vector

$$
\mathrm{v}=\left(\mathrm{v}_{1}, \mathrm{v}_{2}, \ldots, \mathrm{v}_{\mathrm{m}}\right) \in \mathrm{R}^{\mathrm{m}}
$$

determine the class $\mathrm{K}_{\mathrm{v}}$ of shifts $\mathrm{a}(\mathrm{t})$, but two of them, namely, $v_{s}$ and $v_{1}$ for which $t_{s} \cdot v_{s}$ and $\mathrm{t}_{\mathrm{i}} \cdot \mathrm{v}_{1}$ stand for the minimal and resp. maximal dedicated durations, respectively, among all durations

$$
\mathrm{D}_{\mathrm{v}}=\mathrm{t}_{\mathrm{i}} \cdot \mathrm{v}_{\mathrm{i}}, 1 \leq \mathrm{i} \leq \mathrm{m},
$$

if bond immunizers are choosing portfolio $\mathrm{BP}_{\mathrm{v}}$ * specified in Theorem 1.

However, it seems likely to this author that many bond managers do not immunize their liabilities by means of portfolio $\mathrm{BP}_{\mathrm{v}}{ }^{*}$, but making use of other immunizing barbell portfolios $\mathrm{BP}_{\mathrm{v}}$. Therefore, there is no point that they will be much interested in estimating all coordinates of the vector

$$
\mathrm{v}=\left(\mathrm{v}_{1}, \mathrm{v}_{2}, \ldots, \mathrm{v}_{\mathrm{m}}\right)
$$

if only two of them really matter.

Now we begin to realize that the answer to the question raised in the title of this paper depends on the choices made by bond immunizers. If they immunize their liabilities by choosing barbell portfolios paying cash at instances $t_{i}$ and $t_{j}$ such that

$$
\text { (a) } \mathrm{v}_{\mathrm{i}}<1, \mathrm{v}_{\mathrm{j}}<1 \text { or (b) } \mathrm{v}_{\mathrm{j}}>1, \mathrm{v}_{\mathrm{j}}>1
$$

then such bond immunizers diminish the chances that Macaulay duration

$$
\mathrm{D}=\sum_{\mathrm{i}=1}^{\mathrm{i}=\mathrm{m}} \mathrm{t}_{\mathrm{i}} \mathrm{w}_{\mathrm{i}}
$$

reducing in case of barbell portfolios to the formula 


$$
\mathrm{D}=\mathrm{t}_{\mathrm{i}} \mathrm{w}_{\mathrm{i}}+\mathrm{t}_{\mathrm{j}} \mathrm{w}_{\mathrm{j}}
$$

accurately approximates the dedicated duration

$$
\mathrm{D}_{\mathrm{v}}=\mathrm{t}_{\mathrm{i}} \mathrm{w}_{\mathrm{i}} \mathrm{v}_{\mathrm{i}}+\mathrm{t}_{\mathrm{j}} \mathrm{w}_{\mathrm{j}} \mathrm{v}_{\mathrm{j}} \text {. }
$$

But if they select such barbell portfolios $\mathrm{BP}_{\mathrm{v}}$ for which $\mathrm{v}_{\mathrm{i}} \cdot \mathrm{v}_{\mathrm{j}}=1$ or the product $\mathrm{v}_{\mathrm{i}} \cdot \mathrm{v}_{\mathrm{j}}$ is close to 1 $\left(\mathrm{v}_{\mathrm{i}} \cdot \mathrm{v}_{\mathrm{j}} \approx 1\right)$, then the dedicated duration and Macaulay duration become closer to each other.

\section{Comment 3}

The natural question arises how much (to what extend) the weights given by Equation (27), with $\bar{x}_{\mathrm{s}}$, $\overline{\mathrm{x}}_{1}$ meaning the same as $\mathrm{w}_{\mathrm{s}}$ and $\mathrm{w}_{1}$ above, differ from the weights

$$
\mathrm{x}_{\mathrm{s}}=\frac{\mathrm{t}_{1}-\mathrm{q}}{\mathrm{t}_{1}-\mathrm{t}_{\mathrm{s}}} \quad \text { and } \quad \mathrm{x}_{1}=\frac{\mathrm{q}-\mathrm{t}_{\mathrm{s}}}{\mathrm{t}_{1}-\mathrm{t}_{\mathrm{s}}}
$$

derived from the Macaulay duration when $\mathrm{v}=(1,1$, $\ldots, 1)$. Various approaches can be used to answer this question. Some of them may involve knowledge of historical data, while the other may rely solely on simulation techniques independent on the history of shifts $a(t)$ of the term structure $s(t)$.

Open Problem: Is the Macaulay duration the best choice among all dedicated durations $\mathrm{D}_{\mathrm{v}}$ ? In what sense the best? Call this the question Q. To give answer to question $\mathrm{Q}$, one may attempt to approach it by answering the following subquestions:

(a) Is the relationship

$$
\begin{aligned}
& \text { (i) } \mathrm{v}_{\mathrm{s}} \cdot \mathrm{v}_{1}=1 \text { or } \\
& \text { (ii) } \mathrm{v}_{\mathrm{s}} \cdot \mathrm{v}_{1} \approx 1
\end{aligned}
$$

sufficient for the positive answer to question Q ?

(b) Suppose that the weights (27) of the barbell portfolio $\mathrm{BP}_{\mathrm{v}} *$ with the highest convexity differ "very little" from the weights

$$
x_{s}=\frac{t_{1}-q}{t_{1}-t_{s}} \text { and } x_{1}=\frac{q-t_{s}}{t_{1}-t_{s}} \text {. }
$$

Does this guarantee the positive answer to question Q? (c) Suppose that the weights

$$
\mathrm{x}_{1}=\frac{\mathrm{t}_{\mathrm{j}} \mathrm{v}_{\mathrm{j}}-\mathrm{q}}{\mathrm{t}_{\mathrm{j}} \mathrm{v}_{\mathrm{j}}-\mathrm{t}_{\mathrm{i}} \mathrm{v}_{\mathrm{i}}} \text { and } \mathrm{x}_{2}=\frac{\mathrm{q}-\mathrm{t}_{\mathrm{i}} \mathrm{v}_{\mathrm{i}}}{\mathrm{t}_{\mathrm{j}} \mathrm{v}_{\mathrm{j}}-\mathrm{t}_{\mathrm{i}} \mathrm{v}_{\mathrm{i}}}
$$

of some (or many) other than $\mathrm{BP}_{\mathrm{v}}$ * barbell portfolios immunized against shifts a(t) from class $\mathrm{K}_{\mathrm{v}}$ differ "very little" from the weights

$$
x_{1}=\frac{t_{j}-q}{t_{j}-t_{i}} \quad \text { and } \quad x_{2}=\frac{q-t_{i}}{t_{j}-t_{i}} .
$$

Does this guarantee the positive answer to question Q ?

(d) When the answer to question Q will be negative?

\section{$7 \quad$ References}

[1] Bansal, R., Zhou, H., 2002. Term Structure of Interest Rates with Regime Shifts. Journal of Finance. 57(2002), pp.1997-2043.

[2] Elton, E.J., and Gruber, M.J., 1995. Modern Portfolio Theory and Investment Analysis. New York: Wiley.

[3] Fisher, L., and Weil, R., 1971. Coping with the Risk of Interest Rate Fluctuations: Returns to Bondholders from Naive and Optimal Strategies. Journal of Business, 44(1971), pp.408-431.

[4] Jorion, P. and Khoury, S., 1996. Financial Risk Management: Domestic and International Dimensions. Cambridge, MA: Blackwell Publishers.

[5] Litterman, R. and Scheinkman, J., 1991. Common Factors Affecting Bond Returns. Journal of Fixed Income, 54(1991), pp.54-61.

[6] Maculay, R., 1938. Some Theoretical Problems Suggested by the Movements of Interest Rates, Bond Yields and Stock Prices in the U.S. Since 1856. National Bureau of Economic Research, New York.

[7] Redington, F., 1952. Review of the Principle of Life Office Valuations. Journal of the Institute of Actuaries, 3(1952), pp.286-315.

[8] Rządkowski, G. and Zaremba, L., 2000. New Formulas for Immunizing Durations. The Journal of Derivatives, 8(2000), pp.28-36. 
[9] Rządkowski, G. and Zaremba L., 2010. Shifts of the Term Structure of Interest Rates Against Which a Given Portfolio Is Preimmunized. Control and Cybernetics, 39(2010), pp.857-867.

[10] Zaremba, L., 1998. Construction of a k-immunization Strategy with the Highest Convexity. Control \& Cybernetics, 27(1998), pp.135-144.

[11] Zaremba, L. and Smoleński, W., 2000. How to Find a Bond Portfolio with the Highest Convexity in a Class of Fixed Duration Portfolios. Bulletin of the Polish Academy of Sciences, 48(2000), pp.279-286.
[12] Zaremba, L. and Rządkowski, G., 2016. Determination of Continuous Shifts in the Term Structure of Interest Rates Against Which Bond Portfolio B is Immunized. Control \& Cybernetics, No. 4 (in the publishing process).

[13] Zheng, H., Thomas, L. and Allen, D., 2002. The Duration Derby: A Comparison of Duration Based Strategies in Asset Liability Management. Proceedings of $41^{\text {st }}$ IEEE Conference on Decision and Control, Las Vegas, Nevada USA.

[14] Zheng, H., 2007. Macaulay Durations for Nonparallel Shifts. Annals Operation Research, 151 (2007), pp.179-191. 